\title{
Patient Safety in Ophthalmology
}

\author{
Myrta Lippera, Jacques Bijon, Chiara Eandi, \\ and Gianni Virgili
}

\section{Learning Objects and Questions Covered in the Chapter}

- Patient safety in the field of surgical ophthalmic care.

- Intraoperative and postoperative adverse events of cataract surgery and intravitreal injection therapy, possible prevention strategies, and management of the complications.

- Patient care and assessment prior, during, and after ophthalmic surgery.

- How to improve the surgical training process.

- Introduction to ophthalmic surgical errors and implications for the patient and the surgeon, with special focus on cataract and intravitreal injection therapy.

- How medical errors occur: the Swiss Cheese model of system accident.

Myrta Lippera and Jacques Bijon contributed equally so both are co-first author.

M. Lippera · G. Virgili

Eye Clinic, Department NEUROFARBA, Careggi

University Hospital, University of Florence,

Florence, Italy

e-mail: gianni.virgili@unifi.it

J. Bijon $(\bowtie) \cdot$ C. Eandi

Department of Ophthalmology, University of

Lausanne, Lausanne, Switzerland

Jules-Gonin Eye Hospital, Fondation Asile des

Aveugles, Lausanne, Switzerland

e-mail: Jacques.bijon@fa2.ch;

chiara.eandi@fa2.ch
- Causes and risk factors of wrong site surgery and preventing strategies.

- How to avert medication-related errors.

\subsection{Introduction}

In the "Guidance on Patient Safety in Ophthalmology," the Royal College of Ophthalmologists (RCO) defines patient safety as "the process by which an organization makes patient care safer. This should involve the following: risk assessment; the identification and management of patient-related risks; the reporting and analysis of incidents; and the capacity to learn from and follow-up on incidents and implement solutions to minimize the risk of them recurring" [1].

Patient safety is particularly relevant in ophthalmology and regards the surgical part more than the clinical one. In particular, the Veteran Health Administration (VHA) reported in 2009 and 2011 that ophthalmology was the specialty with the highest number of incorrect surgical procedures [2]. However, Mayo Clinic defines ophthalmic surgery, and in particular cataract surgery, as safe for patients. This apparent contradiction is due to the fact that cataract surgery is a very common operation, and thus even rare adverse outcomes are frequent in absolute terms.

According to the World Health Organization (WHO), cataract causes $51 \%$ of world blindness. 
In 2010 this condition represented about 20 million people. In fact, in many countries barriers exist that prevent patients to access surgery. Nonetheless, worldwide approximately ten million surgeries are performed each year. In economically well-developed countries, cataract surgeries were performed at a rate of 4000-6000 per million population annually in 2000 [3]. In 2011, in the United States of America (USA), the rate reached 1100 per 100,000 residents and the number of people who undergo cataract surgery seems to grow steadily [4].

In the same way, the amount of intravitreal injections continues to increase year by year [5]. Between 2010 and 2015 it was registered in England a $215 \%$ rise of anti-VEGF injections and 388,031 procedures were registered between 2014 and 2015 [6]. In 2016 it was reported that 5.9 million injections were administered only in the USA [5].

Since the two mentioned procedures are the most common and consequently the ones that contribute the most to adverse events and errors in the ophthalmic practice, they will be the focus of the chapter.

\subsection{Epidemiology of Adverse Events: Safety Practices and Implementation Strategy}

\subsubsection{Cataract Surgery}

Greenberg et al. reported the prevalence of ocular complications associated with cataract surgery in 45,082 United States veterans. The study showed that $3.8 \%$ patients had intraoperative ocular complications and $9.8 \%$ patients had postoperative ocular complications within 90 days from surgery. The most common intraoperative ocular complications were posterior capsular tear and vitreous loss, sometimes both (3.5\%). The most common 90-day postoperative ocular complication was posterior capsular opacification (4.2\%). Cystic macular edema (3.3\%) and retained lens fragments $(1.7 \%)$ followed [7].
Ophthalmology trainees execute $21-39 \%$ of all the cataract surgeries performed in developed countries $[8,9]$. It is interesting to notice that, with proper supervision and patients' selection, cataract surgery performed by residents have a similar risk of complications to cataract surgery performed by attending staff. In detail, Rutar et al. reported a major intraoperative complication rate of $4.7 \%$ in cataract surgery performed by residents in the USA, the rate included $3.1 \%$ cases of vitreous loss [10]. The USA Accreditation Council for Graduate Medical Education (ACGME) assessed at 86 the required minimum number of procedures as primary surgeon for graduating residents in ophthalmology [11].

Similarly, a study conducted in Australia found no difference in the rate of posterior capsule tear, vitreous loss, or dropped lens rates between trainees and consultants. However, an increased rate of wound burns when trainees were operating was registered $(2.2 \%$ versus $0.4 \%)$ [12].

The same trend was confirmed by a Canadian study [13]. Unfortunately, further recent studies regarding the complication rate of cataract surgery performed by residents are missing in other countries, for instance Europe.

Therefore, the reported data might not reflect the standards worldwide. Nevertheless, it can be said that residents can always add a positive value to the quality of patient's care. As a matter of fact, trainees often spend additional time with patients and create a supportive relationship with them. This attitude improves patient experience before surgery, with a more attentive preoperative assessment for risk factors. In addition, there are also benefits after surgery, with increased vigilance for postoperative complications [14].

\subsubsection{Intraoperative Adverse Events}

- Local anesthesia is nowadays the technique most frequently used. In specific it is performed in $95.5 \%$ of cataract surgeries. In particular, topical and sub-Tenon anesthesia are considered effective and safe procedures [15]. In fact, sub-Tenon anesthesia consists in the 
insertion of a blunt cannula in the episcleral space in order to release the anesthetic. Topical anesthesia consists in administration of anesthetic eye drops.

On the contrary, retro-bulbar and peri-bulbar anesthesia imply the use of a sharp needle to inject the anesthetic [16]. This action can lead to sporadic but serious adverse events like retrobulbar hemorrhage $(0.03 \%)$, globe injury $(0.01 \%)$, and, more rarely, optic nerve atrophy, muscular palsy, and brain-steam anesthesia [17].

The main adverse event of topical and subTenon anesthesia is patient discomfort or ocular pain during and after the procedure. A Cochrane review established that topical anesthesia showed intensification of intraoperative pain and decrease of postoperative pain at $24 \mathrm{~h}$, when compared to sub-Tenon's anesthesia. Since there was not enough evidence to declare which of the two techniques was associated with less intraoperative complications, both types of anesthesia can be considered adequate for cataract surgery [16].

- Posterior capsule rupture (PCR) incidence rate has recently decreased due to the introduction of advanced techniques, newer instrumentation and technology. It is the most common intraoperative complication and in uncomplicated cases of cataract surgery can range from $1.9 \%$ [18] to $3.5 \%$ of [7]. It can lead to consequences such as vitreous loss (1-5\%), drop of lens fragments or nucleus in the vitreous, placement of the intraocular lens in the ciliary sulcus or anterior chamber, and occasionally the need for additional surgical interventions [19].

Intraocular risk factors for PCR include: pseudoexfoliation syndrome; small pupils and reduced working place; excessive anterior chamber depth, which can occur in high myopic eyes or after pars plana vitrectomy; certain types of cataract, as posterior polar ones; dense asteroid hyalosis; etc. [20].

The American Academy of Ophthalmology (AAO) described cardinal signs that can help a non-expert surgeon in recognizing PCR: sud- den deepening of the anterior chamber, momentary pupillary dilatation, excessive movement of the nucleus that do not come toward the phaco tip, or vision of a focal sharp red reflex.

Recommendations in order to prevent PCR include considering intracameral phenylephrine in floppy iris syndrome; small capsulorhexis enlargement before hydrodissection; application of one of the existing different techniques in case of rhexis tears [20]; and use of capsular tension rings whenever the capsular bag is unstable or in case of zonular dehiscence [21]. Moreover, a thorough knowledge of phacoemulsification machine and its parameters is essential both to prevent and manage unexpected events while operating [20].

In the eventual case of PCR, the National Institute for Health and Care Excellence (NICE) suggests following a protocol. The protocol should include: removing vitreous from the wound and anterior chamber; minimizing traction on the retina; removing lens fragments in the posterior chamber or vitreous cavity when possible; removing soft lens matter; and proceeding to intraocular lens (IOL) insertion when possible [21].

In conclusion, identifying the presence of predisposing factors, early recognition, and appropriate modification of the surgical plan can decrease the overall incidence of PCR.

\subsubsection{Postoperative Adverse Events}

- Posterior capsular opacification (PCO) rate varies in literature from 3\% [22] to 47\% [23, 24]. PCO is caused by migration toward the posterior capsule, proliferation, and differentiation of the residual lens epithelial cells on the anterior capsule [25]. Young age is a significant risk factor for PCO [26]. Surgeryrelated factors that can be modified in order to prevent PCO are: achieving good hydrodissection and cortical cleanup, implanting both haptics in the capsular bag, performing a continuous curvilinear capsulorhexis diameter 
which should be slightly smaller than the IOL optic diameter [22].

The treatment is provided by YAG capsulotomy, a noninvasive, quick, and effective technique. However, it should be remembered that YAG capsulotomy can cause rare but possible risks, including retinal detachment, damage to the IOL, cystoid macular edema, increase in intraocular pressure, iris hemorrhage, corneal edema, IOL subluxation, and exacerbation of localized endophthalmitis [27]. A follow-up after YAG capsulotomy is therefore recommended.

- Retinal detachment (RD) rate is described being between $0.26 \%$ at 1 year [28] and $1.79 \%$ at 20 years from cataract surgery [29].

It was hypothesized to be caused by postsurgical anatomical and biochemical alterations in the vitreous [30]. Specifically, the smaller volume of IOL, compared to the volume of the cataractous lens, increases the total vitreous volume and consequently mobility of the vitreous [31]. Moreover, biochemical changes and alterations in the protein composition of the vitreous fluid after phacoemulsification contribute to the development of retinal disease [32].

Predisposing factors are young age, male gender, long axial length, and intraoperative complications, like capsular tear with vitreous loss [33]. Pars plana vitrectomy for removal of posteriorly dislocated lens fragments was additionally associated with a significantly shorter time interval between cataract surgery and retinal detachment (3.9 versus 15.7 months) [34].

Whenever this complication occurs, the patient should be immediately referred to a vitreoretinal surgeon. Haddad et al. showed achievement, after retinal reattachment, of 20/60 best-corrected visual acuity (BCVA) or better in only $50 \%$ of cases [34].

- Cystoid macular edema (CME) is a frequent cause of decreased BCVA after uncomplicated cataract surgery [35]. The incidence of $\mathrm{CME}$ in patients without risk factors was $1-2 \%$ [36]. However, its incidence has been reported to be between $1 \%$ and $30 \%$, due to the heterogeneity of diagnostic criteria. In addition, its rate can be increased whenever other ocular comorbidities are present, like diabetes, previous CME, previous retinal vein occlusion, epiretinal membrane or by prostaglandin use [37].

CME is normally a self-limiting condition: 95\% of CME due to Irvine-Gass, or postcataract $\mathrm{CME}$, has been shown to resolve within 6 months without additional therapy. Some cases, however, can determine longterm visual impairment [37]. The NICE recommends the use of topical steroids in combination with non-steroidal antiinflammatory drugs (NSAIDs) in order to manage CME. Moreover, NICE recommends their use after cataract surgery for people at increased risk of cystoid macular edema, for example, people with diabetes or uveitis [21].

In 2015, Kim et al. reported that topic NSAIDs hasten the speed of short-term visual recovery after cataract surgery when compared with placebo or corticosteroid eye drop with limited intraocular penetration. However, at 3 months or more, prophylactic use of NSAIDs showed lack of evidence in reducing CME-related vision loss [38]. A 2016 Cochrane review concluded that topical NSAIDs can be useful in preventing CME, but possible effects on postoperative BVCA are uncertain [39]. In 2018 the European Society of Cataract \& Refractive Surgeons (ESCRS) PREMED Study I reported that use of topical bromfenac $0.09 \%$, compared with topical dexamethasone $0.1 \%$, can lower macular thickness and total volume after uneventful cataract surgery in patients with no risk factors for CME. However, a reduced risk of developing clinical significant macular edema was shown in eyes treated with combination of the two drugs, compared with patients treated with a single drug [40, 41].

- Suprachoroidal Hemorrhage (SCH) is a sight-threatening complication where blood accumulates between the choroid and the sclera. The etiopathogenesis is long or short posterior ciliary arteries rupture [19, 42]. It is defined as a hemorrhage that can cause extru- 
sion from the eye of the intraocular contents, or that can force the inner retinal surfaces into or near apposition [42]. The incidence varies from $0.03 \%$ to $0.28 \%$, in the case of extracapsular cataract extraction [42, 43]. Risk factors include myopia, glaucoma, diabetes, atherosclerotic vascular diseases, and hypertension [42].

Clinical signs of an intraoperative choroidal hemorrhage include shallowing of the anterior chamber, iris prolapse, expulsion of the lens and vitreous outside the eye, and dark retinal and choroidal detachment with loss of the red reflex [44]. Whenever it occurs, the surgical wound should be immediately closed with sustainable sutures [42]. As systemic hypertension is also a risk factor, intravenous administration of hypotensive agents might help in patients with high blood pressure.

In case of massive $\mathrm{SCH}$, with BVCA of light perception, surgical interventions such as transcleral drainage, vitrectomy, and silicone oil tamponade are valuable options to improve the poor prognosis [45].

Consideration of all risk factors and avoidance of predisposing events are a priority in order to prevent $\mathrm{SCH}$.

- Endophthalmitis is a severe infective inflammation of intraocular fluids. It is frequently a postoperative complication but can also occur after traumas. Rarely it can be sterile or with an endogenous etiology, arising from systemic infections or inflammatory disorders [46].

The epidemiology of post-cataract endophthalmitis varies in the literature. A systematic review conducted by Taban et al. reports an overall endophthalmitis rate of $0.128 \%$ between the years 1963 and 2003. Specifically, a $0.327 \%$ rate occurred in the $1970 \mathrm{~s}, 0.158 \%$ in the $1980 \mathrm{~s}, 0.087 \%$ in the $1990 \mathrm{~s}$. It is interesting to notice that a $0.265 \%$ rate was registered between 2000 and 2003 [47]. On the contrary, the ESCRS endophthalmitis study group reported a decrease of postoperative endophthalmitis from rates near $0.3-1.2 \%$ to $0.014-0.08 \%$ after the institution of intracameral cefuroxime [48].
The main finding is a red eye with blurred vision. Although an aching eye is often present, $25 \%$ of the patients do not complain of pain. Signs include hypopyon (85\% of cases) and hazy media ( $80 \%$ of cases) [49].

The mainstay treatment is with antibiotic intravitreal injections; vancomycin and ceftazidime are the first choice. The Endophthalmitis Vitrectomy Study (EVS) showed no benefits in systemic intravenous antibiotics administration [49]. On the contrary, in case of severe purulent infections the ESCRS Guidelines for Prevention and Treatment of Endophthalmitis encourage the prescription of a systemic antibiotic therapy, not necessarily intravenous. For those cases, the same drug class from the one contained in the intravitreal therapy should be administered [50].

BCVA was a discriminant factor for endophthalmitis management. In 1995 the EVS reported that only patients presenting with a visual acuity of light-perception showed benefit from immediate core vitrectomy. However, more recently Kuhr suggested offering a complete vitrectomy whenever those clinical signs were present: poor red reflex or no detection of retinal details, no improvement after $24 \mathrm{~h}$ from intravitreal injection [51, 52]. The study is, however, conducted on a limited number of patients and it is not randomized.

\subsubsection{Safety Practices and Implementation Strategy in Cataract Surgery}

\section{A. Preoperative Care}

\section{Patient Assessment}

NICE guidelines recommend using optical biometry for axial length measurements [21]. In facts, this technique is easy and quick to perform. It is automated, user-independent, and precise, since the patient is fixating on a target while the measurement is taken $[53,54]$. However, its limitation is due to the fact that the machine uses an average velocity to determine the eye axial length, which is extrapolated from the time 
needed by the pulse waveform to cover the cornea-retina distance. Due to this, in an eye longer than $26 \mathrm{~mm}$ the real axial length could be overestimated, and the opposite could occur in an eye shorter than $22 \mathrm{~mm}$. In those cases, special formulas are required to balance the final calculation.

Ultrasound biometry is nowadays necessary when optical biometry pulse waveform does not manage to measure the axial length, for example, in case of very dense cataracts or vitreous hemorrhage; or whenever the optical biometry results cannot be considerate precise, as it can occur in case of macular retinal detachment.

Corneal topography should be used whenever any abnormality of the cornea surface is present or suspected: high or low K-values, high astigmatism, keratoconus, etc. In particular, topography should be performed in case of a precedent refractive surgery correction. Since the relationship between the anterior and posterior curvature is iatrogenic modified in those eyes, additional calculations and sometimes more than one intervention can be necessary to achieve the desired refractive target [21].

\section{Supplemental Evaluation}

Patient comorbidities can worsen and cause systemic adverse events during or after cataract surgery. Cavallini et al. registered those complications to occur in $0.63 \%$ of cataract cases, in particular arterial hypertension showed to complicate the $0.31 \%$ of the surgeries [55]. Systemic adverse events are a matter of concern, in terms of absolute numbers, due to the large number of elderly who undergo cataract surgery with cardiac or pulmonary diseases [56]. In the past decade, the request of blood test results and of an electrocardiogram prior to surgery was common. Nowadays, different geographical areas have various approaches.

The AAO Preferred Practice Pattern, as well as the RCO Guidelines and the National Health Service (NHS), discourages asking for routine exams before cataract surgery $[21,53,57]$. But, in case of serious comorbidities, the AAO advises requiring supplemental testing and a systemic visit [53].
On the other hand, in 2019 a Cochrane review certified that routine preoperative testing does not increase the safety of cataract surgery in terms of total medical adverse events, total hospitalization, total deaths, cancellation of cataract surgery, and total ocular adverse events. As an alternative, questionnaires about general health can be administered and completed by the patient or the primary care physician. Doing so, a better identification of patients at risk of systemic adverse events is possible [56].

\section{Risk Stratification}

NICE Guidelines suggest relying on a validated risk stratification system in the preoperative assessment. If a high surgical risk is identified, its implications and the new risk-benefit ratio for surgery should be discussed with the patient. Whenever an unsuccessful surgery could have a severe impact on life, as it might be for instance in monocular vision, surgical risks should be attenuated and a close supervision is necessary if a trainee is performing the surgery [21].

Muhtaseb et al. developed a risk stratification system by reviewing different risk factors for cataract surgery from the literature and associating a value to each of them. According to the total sum of the points related to single risk factors, each patient was categorized into a risk group predictive of intraoperative complications: group 1 with no added risk; group 2 with low risk; group 3 with moderate risk; and group 4 with high risk. In addition to individualized counseling, risk stratification can be useful to select cases that could be operated by nonexpert surgeons and to standardize patients in groups for scientific studies [9].

Butler et al. described a similar system with weighted scores based on the severity of risk factors reported by Narendran et al [58, 59]. Scores less than 3 are appropriate for junior trainees; cases scoring from 3 to 5 are appropriate for more senior trainees; and cases scoring higher than 5 for consultants [58]. Although this system was meant to predict intraoperative complications, a correlation was also observed between the score and postoperative complications, as well as postoperative corrected-distance visual acuity out- 
comes [60]. Other risk stratification systems exist, like the New Zealand Cataract Risk Stratification or the Najjar-Awwad cataract surgery risk score for resident phacoemulsification surgery [60-62].

\section{B. Perioperative Care}

\section{Patient Alimentation and Therapy}

The Joint Guidelines from the RCO and the Royal College of Anesthetists declared that it is not mandatory for patients to be fasted the day of the surgery in case of topical anesthesia without sedation. As a matter of fact, no aspiration event was ever described. In detail, a special attention is required for diabetic patients in therapy with insulin. For them, local protocols should be developed in order to avoid hypoglycemia, considering also catering whenever the surgery is going to be performed late in the day [63].

The RCO also suggests to tell patients to take their normal medication on the day of the surgery [57, 63]. In particular, a review conducted in 2015 showed how continuation of anticoagulant and antiplatelet therapy before and during an uncomplicated cataract surgery is safe. However, in case of small pupils, floppy iris syndrome, iris neovascularization, significant pseudoexfoliation, or phacodonesis, discontinuation of the therapy can be discussed with an internist or cardiologist [64]. Indeed, Warfarin increases the risk of orbital hemorrhage from $0.2 \%$ to $1.0 \%$ [57]. It might also increase other hemorrhagic complication risk, like hyphema, dot retinal or retrobulbar and choroidal hemorrhages [64]. In addition, anticoagulant exposure worsen the severity of an already onset bleeding [65]. Nevertheless, it was demonstrated that warfarin reduces lifethreatening thrombotic events and decreases the risk for stroke to 1 in 100 [57]. Therefore, when older oral anticoagulants are used, the International Normalized Ratio (INR), when possible, should remain in the desired therapeutic range [57].

\section{Prophylaxis of Infections and Sterility}

Endophthalmitis prevention is crucial. The ESCRS Endophthalmitis Study Group demonstrated that the risk for contracting postoperative endophthalmitis was reduced by an intracameral injection of $1 \mathrm{mg}$ cefuroxime at the end of the surgery. The lowest incidence rate of endophthalmitis was observed in the group who received, in addition to intracameral cefuroxime, an intensive pulsed dose regimen of three drops levofloxacin, each drop separated by $5 \mathrm{~min}$, also given at the close of surgery, along with two drops given preoperatively, $30 \mathrm{~min}$ apart $[50,66]$. A Cochrane review confirmed, with high-certainty evidence, the role of intracameral cefuroxime for prevention of intraocular infections. On the other hand, the perioperative use of antibiotic eye drops, levofloxacin or chloramphenicol, showed to lower the possibility of endophthalmitis only with moderate certainty evidence [46].

Since the patient's own ocular surface flora contains also pathogenic microorganisms that can infect the eye during surgery, preoperative antisepsis is an important point in prophylaxis [67]. Prior to the start of operation, the surgeon must irrigate the cornea, conjunctival sac and periocular skin with povidone-iodine $5 \%$ ophthalmic solution, or chlorhexidine $0.05 \%$ in case of allergy [50]. In this way, the microorganisms of patient ocular flora are reduced up to $90 \%$. The application of the antiseptic for at least $3 \mathrm{~min}$ before surgery showed to decrease the postoperative endophthalmitis rate $[50,68]$.

A systematic review demonstrated that, excluded patient ocular flora, another cause of postoperative endophthalmitis is contamination from the surgical environment. In particular, it occurs from solutions, phacoemulsification machines, ventilation systems, and defective sterilization of ocular surgical instruments [69]. Consequentially, endophthalmitis prevention includes standardized quality control systems, surveillance, and infection control measures in the operating theater. Regular maintenance of proper filters in the airflow systems is mandatory. In the same way, maintenance of closed doors during surgery is recommended and a constant positive pressure in the room should always be present. Bacterial filters on bottles of solutions are necessary since wet areas are easily contaminated with Pseudomonas aeruginosa, which leads to a particularly severe form of endophthalmitis [50]. All instruments must be limited to single use and 
washed properly prior to sterilization. More recommendations regarding intraocular surgical instruments cleaning and sterilization can be found in the article written by Hellinger et al. [70].

\section{Postoperative Care}

After surgery, teaching the patient which symptoms might be an early sign of a possible complication is crucial for fast access to emergency care. In particular, it should be remarked that significant reduction in vision, increasing pain, progressive redness, or periocular swelling could indicate a possible intraocular infection [53].

Since it was demonstrated that, in case of an uncomplicated operation, a visit within $24 \mathrm{~h}$ from surgery did not reduce the rate of severe adverse events, a first postoperative visit postponed at 2 weeks did not seem to increase the postoperative risk [71, 72]. However, a 24-h check is still recommended in patients who underwent intraoperative complications, have high postoperative risk, or have monocular vision [53].

Moreover, during the postoperative visits, a dilated fundus examination is not mandatory since the incidence of peripheral retinal findings at 1 month after cataract surgery was demonstrated to be low $[53,73]$. However, it should be performed whenever a posterior segment complication is suspected or in patients with high risk of peripheral retinal pathologies like diabetic retinopathy, retinal vein occlusions, or high myopia [74].

According to the AAO, "the surgeon's obligation to the patient is not discharged with the conclusion of a successful operation. Unless terminated by the parties, his relationship to the patient continues until ended by the cessation of the necessity which gave rise to the relation." Therefore, the same ophthalmologist who performed the surgery should provide postoperative eye care. Whenever this is not possible, the patient can be referred to another ophthalmologist only with agreement between the three figures involved: the patient and the two ophthalmologists [75].

\section{Training}

The ACGME states that trainees approaching the end of their ophthalmic residency should be able to perform the diagnostic, medical, and surgical procedures expected for an ophthalmologist entering a comprehensive ophthalmic practice [76]. This goal has to be achieved always providing high-quality patient care.

The ACGME also exhorts University Hospitals to build their own Ophthalmic Educational Programs. Each program should include goals for the trainee. The aims cannot be standardized since they depend on the needs of the community where the hospital works, on the hospital working team propensity toward specific ophthalmic fields, as well as on the resident talent or inclination. Because of this, the Program may be more focused on research, leadership, public health, etc. Nevertheless, faculty members should approve it and review it regularly [76].

The "Guide for delivery of Ophthalmic Specialist Training (OST)" of the RCO recommends protected time for education. Lessons should be organized, and residents should be able to attend at least one session per week of a regional teaching program. In addition, at least one fully protected research session a week is expected [77].

The International Council of Ophthalmology (ICO) Residency Curriculum, available online, offers an international perspective on what should be taught during residency [78].

Methods to teach and learn surgical procedures are not standardized worldwide. Moreover, the surgical skills and possibility to learn for residents vary widely among the residency training programs and even within the same program. For instance, in the USA the average number of phacoemulsification performed during residency is about 113 , but it might vary from 80 to 140 cases, and $25 \%$ of residents perform fewer than 80 cases; United Kingdom (UK) registered a number of 500-600 cases per resident [79], and Canada a number of 200-400 [79, 80]. However, in other countries less than 50 phacoemulsification are performed at the end of residency.

Implementation strategies to improve the process of training, while reducing risk for the patient, have been proposed [79].

Enhancement made by hospital and program administration might regard expansion of clinic and operating theater where residents work. In addition, teaching should be encouraged, also with incentives. 
Regarding trainers, the RCO strongly exhorts them to regularly attend a course that learns how to teach. Whenever possible, part of the operating lists should be specifically reserved for training, and specific time in the surgery room should be dedicated for junior doctors [81].

Lastly, residents should study and be familiar with the surgical procedures and possible complications [79]. Indeed, they should also actively participate to the pre- and postoperative care [79]. In facts, good data collection with continuous monitoring of complication rates for each individual resident is important, as well as successive audit about the cataract outcomes [81].

Wet labs and surgical simulators should be included in residents' experience in order to improve the trainee learning curve and increase patient safety [82]. In fact, a significant decrease of cataract intraoperative complications was shown in junior surgeons who trained with additional surgical simulator [83].

\subsubsection{Intravitreal Injection Therapy}

Intravitreal injection therapy (IVT) is the treatment of choice for many retinal diseases. This is used mainly in case of choroidal neovascularization in macular degeneration or in case of macular edema, which can be present in diabetic retinopathy or retinal vein occlusion.

Types of drug released mainly belong to the anti-VEGF family, which blocks the vascular endothelial growth factor in order to obtain regression of abnormal vessels, or corticosteroids, which act as a nonspecific antiinflammatory agent, but also showed a role in VEGF downregulation [84].

\subsubsection{Adverse Events, Safety Practices, and Implementation Strategy}

- Ocular hemorrhage is the most frequent adverse event. In fact, subconjunctival hemorrhages can occur in $10 \%$ of intravitreal injections, especially if the patient is under antiaggregant medications [85]. Massive subretinal and choroidal hemorrhages are rare but present in the literature as possible complications [86, 87]. It is important though not to interrupt antiaggregant, neither anticoagulation drugs prior to IVT. In fact, the risk of serious ocular hemorrhage is low. On the contrary, in case of discontinuation the risk of severe thromboembolic events is high [88].

- Endophthalmitis is the most severe of IVT adverse events. The frequency of this complication ranges from $0.02 \%$ to $1.6 \%[89,90]$.

Streptococcus species showed to be the causative pathogen approximately three times more frequently when compared with intraocular surgery. The bacteria can be isolated in the salivary flora, indeed aerosolization or droplet spread can be the source of operative field contamination. For this reason, talking, sneezing, and coughing should be avoided while performing IVT and a surgical mask should be worn during the whole procedure [89].

Streptococcus mitis or oralis were also found in unused syringes of Bevacizumab. Bevacizumab is an anti-VEGF approved by the Food and Drug Administration for colon-rectal cancer metastasis. Nevertheless, this drug showed good results also in case of neovascular macular degeneration, for which it might be used off-label [91]. On one hand, Bevacizumab use reduces public health care costs due to its price 4-40 times lower than the on-label drugs. On the other hand, in order to reduce the costs, the drug needs to be repackaged for intravitreal injections by the local pharmacy. This action increases the risks of contamination, and therefore protocols and guidelines which stress the need of asepsis during syringe preparation have been made available [92].

Other strategies to reduce the rate of postinjection endophthalmitis are treatment of patient's external infections like conjunctivitis or blepharitis, use of $5 \%$ povidone-iodine, and avoidance of needle contact with eyelids or lashes by the use of a blepharostat [93].

A systematic review conducted in 2018 showed that topical antibiotic prophylaxis prior to IVI injections does not reduce the rate of risk for endophthalmitis [94].

- Sterile intraocular inflammation frequency ranges from $1.4 \%$ to $2.9 \%$ [95]. It is an acute 
ocular reaction without infection; consequently it can be treated with topical steroids and showed good visual outcomes at resolution [96]. This condition goes in differential diagnosis with endophthalmitis, although it is more frequent. Signs that might help a correct diagnosis include:

- Time of presentation: 2.55 days (between 1 and 6 days) for endophthalmitis versus 1 day or less in ocular inflammation.

- Symptoms: decreased vision and severe pain are more frequently associated with endophthalmitis.

- Severity of anterior chamber reaction and vitreitis.

However, it is recommended to administer early intravitreal antibiotic injections whenever a high infection suspicion is present [97].

- Rhegmatogenous retinal detachment (RRD) incidence was around $0.013 \%$ as reported by Meyer et al. [98]. The hypothesized cause is the vitreous detachment due to an incorrect injection technique. For this reason, particular attention to the site of injection and use of small needles are required [93].

- Intraocular pressure (IOP) acute and transitory elevation, lasting maximum some hours and with individual variations, is caused by the injection of fluid in the eye [99]. However, cases of sustained IOP elevation following anti-VEGF have been described, although they are rare [100]. On the contrary, intravitreal injections of corticosteroids, and in particular of Dexamethasone, showed to cause chronic ocular hypertension in almost one out of three patients [101]. Risk factors are a family history for glaucoma or previous glaucoma diagnosis. Regular check of IOP after intravitreal injection is recommended. Fifty percent of all cases with chronic IOP elevation did not require any treatment, while topical hypotensive drugs were needed in most of the other cases and a glaucoma surgery was rarely performed [101].

- Posterior subscapular cataract is known to be correlated with corticosteroid use [102]. Dexamethasone intravitreal implant showed a role in cataract development and was confirmed by a meta-analysis conducted in 2018 [103].

The setting of care for IVT is not necessarily an operating theater. The procedure can also be safely performed in a suitable sterile room with adequate ventilation system. More information about sterility requirements, patient information and consent, pre-injection checks and preparation, as well as post-injection care can be found in the Ophthalmic Service Guidance for Intravitreal Injection Therapy [104].

\subsection{Most Frequent Errors: Safety Practices and Implementation Strategy}

Since humans are fallible, patient safety cannot only rely on the ophthalmologist experience or proficiency. Reliable systems must be put in place to reduce human errors, considered as events that should never occur (i.e., "never event"). For instance, invasive procedure on the wrong eye, as published in the "Never Events List 2018" by the NHS, is not acceptable [105]. Moreover, the occurrence of even a single "never event" constitutes a red flag.

Thereby, despite being in training, a young ophthalmologist must become aware of this fundamental issue: preventable medical errors are not tolerated, especially in the eye of the patient's opinion [106]. This topic is further significant for a specialty that trains not only physicians but also future eye surgeons.

For instance, as previously said, cataract surgery constitutes one of the most common procedures performed, making it a top priority for error avoidance $[4,107,108]$. Indeed, Neily et al. found 342 reported incorrect surgical procedures from VHA Medical Centers from 2001 to 2006. Ophthalmology was the specialty with the most reported errors, representing 1.8 surgical confusions for every 10,000 cases: wrong IOL implantation occupied the highest percentage [109]. This observation was also reported by Simon 
et al. where $67 \%$ of surgical confusion cases (67/106) were accountable to wrong IOL implantation [106]. Their findings emphasize the importance of awareness among young trainees attending ophthalmological surgery.

In a retrospective analysis of medical professional liability (MPL) claims in the US from 2006 to $2015,2.6 \%$ out of the 90,743 closed malpractice claims were filed against ophthalmologists, with $50 \%$ being accountable to cataract and corneal surgery [110]. Even though this study concluded that compared with other specialties, ophthalmology had a relative low number of malpractice claims (ranked 12th out of 29 specialties in a 10 -year period), it should be reminded that study results on this topic probably represent the tip of the iceberg as many medical errors might be unreported [106, 111, 112]. Furthermore, Ali et al. analyzed a decade of claims due to clinical negligence on the NHS Litigation Authority database for ophthalmology (from 1995 to 2006) [113]: their results estimated that an ophthalmologist of any grade had a $30 \%$ chance to be confronted to a claim in a 10 -year period, representing one medical claim due to malpractice in a 30-year career. An even higher risk was predicted for consultants, with $90 \%$ chance of being faced to a claim in a 10 -year period.

\subsubsection{The Most Common Medical Errors and Preventive Strategies in Ophthalmology}

To be successful at preventing a medical error, knowledge of how it occurs is fundamental. The Swiss Cheese model of system accident, proposed by Reason et al., allows to understand how an incident could happen despite defense mechanisms in place [114]. This model represents a "cumulative act effect" phenomenon. For example, in an elaborate medical system, a series of barriers (metaphorically considered as a slice of cheese) are built to prevent a mishap to occur. However, each barrier has its own dynamic weakness (i.e., holes in a Swiss cheese). Taken individually, they do not create an adverse event for the patient but when the holes of the slices are aligned, there is the opportunity for a given hazard to reach the patient [115]. Those weaknesses come from the combination of two main reasons [114]: active failures and latent conditions. James Reason defines active failures as "the unsafe acts committed by people who are in direct contact with the patient or system," while latent condition "arise from decisions made by designers, builders, procedure writers, and top-level management."

In summary, young trainees could hardly be entirely responsible for an error but can participate in the occurrence of such, especially within a system where many latent conditions lie dormant. It takes minor mistakes from multiple aspects of the management of a patient to provoke a preventable error: thus, every medical action has its importance.

It is important for trainees to be aware of the causes and consequences of possible medical errors (including surgical confusions) in ophthalmology. It would allow implementing strategies from the beginning to prevent such mistakes and thus improve patient safety. The list of medical errors and strategies is non-exhaustive; therefore acknowledging their existence is the very first step toward avoiding malpractice. When properly considered, medical errors are an opportunity to learn. Indeed, this allows for actions to be taken in response to such unfortunate and evitable events. Consequently, this will lead to risk reduction for recurrence.

\subsubsection{Wrong-Site Eye Surgery}

\section{Introduction}

Wrong-site surgery is defined as "surgery on the wrong site or the wrong side, the wrong procedure, the wrong implant, or the wrong patient" [116]. In a large systematic review of surgical never events published in 2015, the median incidence of wrong-site surgery in ophthalmology ranged from 0.5 to 4 events per 10,000 procedures [116]. In comparison, the median incidence for general surgical procedures across seven American studies was 0.09 events per 10,000 procedures with, however, a wide variation in the results. Parikh et al. recently conducted a 
large retrospective cohort study of errors in ophthalmological surgical procedure between 2006 and 2017 [117]: they intended to characterize the incidence, causes and consequences of ophthalmological surgical confusions on patients and specialists. Out of the 143 cases of surgical confusions reported, cataract-related errors occupied the first position. Incorrect eye blocks were the second most common surgical confusions, representing $14.0 \%$ of cases. Incorrect eye procedure was in third position, with incorrect patients or operation (3.5\%) being the fifth. Similarly, these results are consistent with a previous retrospective series of 106 cases investigated by Simon et al. more than 10 years earlier [106]. Indeed, 15 cases had surgery on the wrong eye. Wrong eye block was performed in 14 cases. In another 8 cases, either the operation occurred on the wrong patient or the wrong procedure was performed.

\section{Causes and Risk Factors}

Some examples of common root causes and risk factors for the occurrence of surgical confusion identified among the different studies mentioned include [106, 116, 117]:

- Inadequate time-out: it represented the main cause of surgical confusion according to Parikh et al.

- Inadequate site markings: absent, washed off during preparation, poorly visualized, hidden under surgical capes or drapes.

- Inadequate communication: breakdown of communication between the patient and the surgeon, inadequate communication among staff (e.g., OR schedule changes not adequately communicated to all staff members).

\section{Preventive Strategies}

The following are the main prevention strategies of wrong-site surgery proposed across the studies:

\section{A. The Universal Protocol}

This protocol was introduced by the Joint Commission on Accreditation of Healthcare Organizations in 2004 and is aimed to prevent confusions in all surgical procedures. For instance, Parikh et al. concluded that $64.3 \%$ of ophthalmological cases would have been preventable by using the universal protocol [117]. The same conclusion was initially made by Simon et al. where, conscientiously applied, $85 \%$ of the ophthalmological surgical confusions in their retrospective series of 106 cases could have been prevented [106].

The protocol focuses on three complementary steps [118]: (1) Preoperative verification, (2) site marking, and (3) time-out before starting the surgery [106].

However, the universal protocol does not cover steps prior the surgery day where a lot of negligence can be the cause of medical errors occurring in the OR.

The AAO Wrong-site Task Force has managed to fill this gap by bringing specific recommendations tailored to ophthalmological surgery [119]. Their guidelines are divided into three stages:

1. Steps taken prior to surgery day.

2. Steps taken on the day of surgery.

3. Procedures dependent upon preoperative calculations.

Interestingly, communication is central. Indeed, the first step emphasizes on medical records of the patient with proper surgical data available. It outlines the importance of passing the information adequately between ward or clinic and operative room. Other examples include the active participation of the patient and all staff members especially on the day of surgery. Moreover, adherence to the steps and communication would be facilitated by the use of checklists, further reducing the incidence of wrong-site surgery [118].

Nonetheless, certain issues are yet not covered by these strategies. For instance, Simon et al. suggested that patient confusion could ultimately lead to failure of the protocol's efficacy [106]. Furthermore, if staff members do not take seriously into consideration the time-out, which represents the final step of the universal protocol, it would be ineffective. Thus, prevention strategies are only tools to help reduce risks, but even- 
tually it is the duty of the surgeon to make sure these tools are thoroughly followed.

These basic rules must be learned from the beginning of training in order to ensure their efficient application. For example, the inconsistent engagement of staff members in the WHO surgical safety checklist is thought to contribute to persistence of surgical errors in the NHS. Experience of the surgical safety checklist training was therefore investigated through a survey among UK medical and nursing undergraduates by Kilduff et al. [120]. Students that received teaching about the checklist or that were included in the time-out before the beginning of the procedure had a significant better understanding of the checklist's purpose. Their results, however, highlighted the suboptimal teaching of surgical checklists among undergraduates: they did not meet the WHO minimum standards. They postulated that teaching about perioperative patient safety systems and continuous participation in safety protocols were important skills to be taught early in training. Interestingly, they recommended principles and educational interventions in order to guide such endeavor (introductory lectures, surgical rotations, clinical skills, surgical safety checklist assessment through examination questions and clinical evaluation, etc.). The need for formal assessment in the prevention of surgical errors was already suggested through results from a survey mailed to U.S. ophthalmology residents [121]. Most residents responded that their program provided training in preventing surgical errors, mostly through observation and participation to OR protocols. Hands-on experience was found to be the most effective method. However, a gap still remained in formally assessing residents' knowledge about this subject.

\section{B. Consent Form}

This is entirely a part of the universal protocol as mentioned in the WHO guidelines [118]. Full consent from the patient is mandatory for any procedure. The patient must be awake, alert, and have a full capacity of discernment in order to understand the details and potential complications of the surgery that will be performed. This includes therefore a proper explanation from the physician and an active participation of the patient or representative. Consequently, the site of the surgery and the laterality must be clearly stated and written on the form. Finally, once agreement between the surgeon and the patient has been achieved, the latter must sign the consent form to confirm its approval.

\subsubsection{Cataract Surgery-Related Errors}

\section{Introduction}

Cataract surgery occupies a central part in understanding and preventing medical and surgical errors in ophthalmology. Studies treating about the incidence of surgical confusions in ophthalmology unequivocally agreed that the top surgical error is related to IOL implants. Indeed, the use of incorrect IOL represented $66.4 \%$ of surgical confusion cases in Parikh et al. series [117]; $48.9 \%$ of adverse events in Neily et al. descriptive study [109], and $63 \%$ in the retrospective series of Simon et al. [106]. Interestingly, these results match the number of claims reported in the literature among ophthalmological procedures. For example, two different studies made across the UK showed that one third of malpractice claims filed against ophthalmologists were accountable to cataract surgeons [113, 122]. Moreover, socioeconomic consequences of cataract malpractice are considerable [110]. Therefore, young ophthalmologists must be well prepared regarding legal aspect when starting their surgical training especially in cataract surgery.

\section{Causes and Risk Factors}

In the "Cataract Surgery Guidelines" released by the RCO in 2010 [57], they presented a list of risk factors for unsafe cataract surgery for surgeons to be attentive to. Here are some examples that could lead to medical errors especially for residents:

- Clinical staff not following guidelines or not relying on evidence-based medicine.

- Lack of team working or team training. 
- Lack of appropriate skills.

- Distractions or interruptions during intervention.

- Rushing during surgery with inappropriate focusing on personal performance rather than patient safety and quality of care.

- Lack of patient involvement.

- Poor communication (e.g., of information within the medical file or between the surgeon and the patient...).

Interestingly, such factors have been linked to the occurrence of surgical claims. Ali et al. separated predisposing factors (communication errors, inattention...) from precipitating factors (lack of adequate care, mistakes, system errors...) for litigation [111]. They suggested that in the absence of predisposing factors, precipitating factors are unlikely to lead to litigation in clinical practice. Furthermore, studies have shown that a breakdown in communication is the root cause of up to $70 \%$ of claims [123]. Thus, knowing these causational risk factors for young trainees would reasonably improve patient care by reducing the risk of medical errors occurrence.

There are different stages of the patient care in cataract surgery: (1) identification of refractive goals, (2) biometry measurement, (3) IOL selection, and (4) implantation. These sequential steps involve various staff members in different times. Often, communication is crucial to allow a proper transmission of data. Thus, this complicated process carries out an increased risk for error occurrence. In the following are examples of specific preventable human errors (i.e., never events) that were identified for leading to IOL-related incident [57, 124]:

\section{IOL measurement (biometry, formula)}
(a) Inaccurate biometry
(b) Wrong formula
(c) Failure of routine bilateral biometry measurement
(d) Failure of re-measurement of axial length asymmetry

\section{IOL selection}
(a) Confusion in postoperative refractive goals (e.g., the patient agreed for postop-

erative myopia and the surgeon aimed for emmetropia during surgery)

(b) Wrong-patient biometric data used for surgery

(c) Wrong-eye biometric data used for surgery

(d) Wrong type of IOL data selected (e.g., confusion between anterior chamber and posterior chamber IOL data)

(e) Failure to adequately communicate the selected IOL type and power due to transcription errors

\section{IOL preoperative preparation}

(a) Failure to check availability of the IOL before starting the surgery

(b) Failure to adequately label the IOL box with the correct patient

\section{IOL surgical implantation}

(a) Failure to bring the correct IOL in the OR

(b) IOL confusion due to a second IOL (not belonging to the patient) already present in the OR

(c) Failure to check the IOL characteristics before implantation [106]

(d) Failure to correctly place a toric IOL in the right meridian

Finally, improper use of the universal protocol is also among the errors identified for incorrect IOL placement.

\section{Preventive Strategies}

Examples of preventive strategies could be divided into two definite periods according to the NICE guideline for cataract management in adults (for details, refer to paragraph 1.5, "Preventing wrong lens implant errors") [21]:

\section{The day before the surgery}

(a) Confirm the patient's correct medical notes.

(b) Biometry assessment: confirm that the results belong to the proper patient; use electronic data and transfer the biometry results to the patient's medical record; print the results and fix them appropriately into patient's medical notes. 
(c) Communication with the patient: explain the different types of IOL and their refractive implications; discuss the refractive target; record the IOL chosen by the patient and any specificities mentioned during the discussion.

\section{The day of the surgery}

(a) Have the patient's note, especially biometry results available in the OR.

(b) Use the modified WHO Surgical Checklist: confirm the patient's identity and match the information with the consent form, the biometry results and the medical notes; check and mark the eye to be operated; have only the selected IOL in the OR with one another identical IOL in stock and an alternative type of IOL ready if complications occur. Some of these steps are repeated before anesthesia and one last time before starting the procedure by the surgeon.

(c) Confirmation by two distinct staff members that the IOL formulas, calculations, and constants are appropriate.

Moreover, in attempt to learn from any wrong IOL implantation and establish further preventive strategies, the NICE guidelines advocate for multidisciplinary analysis of actual incidents.

Interestingly, these guidelines are, for instance, based on the IOL safety protocol for routine cataract surgery that is merged with the WHO Surgical Checklist as introduced by the Royal Victorian Eye and Ear Hospital in Australia [124]. Similar strategies were described in the third section of the recommendations proposed by the AAO wrong-site task force, regarding the procedures that are dependent upon preoperative calculations [119].

\subsubsection{Intravitreal Therapy-Related Errors}

\section{Introduction}

Despite IVT being more frequently performed than cataract surgery, studies have shown that there is less surgical confusion occurring during intravitreal injection [117]. Parikh et al. only found one case of an incorrect eye intravitreal injection. An under-report of errors could justify this paradigm. As suggested, the latter could be explained by the procedure being mainly performed by single ophthalmologists in nonhospital-based clinics, a substantial number of patients having bilateral conditions which would therefore minimize the consequence of wrong-side intervention, the procedure itself being of low-risk for complications, and substances used to be similar in action with few adverse effects [117].

\section{Preventive Strategies}

In a retrospective review of anti-VEGF-related incidents from 2003 to 2010 in NHS care, a substantial number of patient safety incidents were accountable to medical and surgical confusions [1]. Some suggestions by the authors to reduce these incidents included electronic patient records or prescriptions, audit tools, or the use of checklists with an appropriate time-out before injection. Therefore, most of medical and surgical confusions related to intravitreal injections belong to the category of "wrong-site surgery" and its preventive strategies.

\subsubsection{Medication-Related Errors in Ophthalmology}

\section{Introduction}

The National Coordinating Council for Medication Error Reporting and Prevention defines medication errors as "any preventable event that may cause or lead to inappropriate medication use or patient harm while the medication is in the control of the health care professional, patient, or consumers (...)." They propose this standard definition to be used by researchers and institutions to better identify errors [125]. Medication errors constitute a common cause for malpractice in medicine. Ophthalmology is thus not spared, especially due to the high volume of prescriptions in this specialty. Indeed, in a large data report collected in the United States in 1995 and 1996 from the National Ambulatory Medical Care Survey, half of ophthalmological consultations in the office resulted in a medication pre- 
scription [126]. Furthermore, a prospective study over a 4-week period that recorded the number of prescription errors at an ophthalmic hospital in the UK found that $8 \%$ of prescription sheets had errors (144/1952) [127]. Therefore, drug prescription is a sensible step in a patient care, especially after a surgical intervention, and identifying the causes and strategies to prevent errors are critical to ensure patient safety.

\section{Causes and Risk Factors}

In the following are highlighted common contributing factors that lead to medication errors as listed in the Communication about Drug Orders released by the AAO in 2015 [128]:

- Lack of information about the patient (e.g., allergies, contraindication) and the drug (e.g., interactions).

- Failure in adequate communication of drug orders (e.g., illegible prescription, improper use of decimal points and zeros, confusion with abbreviations).

- Environmental stress (e.g., fatigue, distractions affecting performance during prescription writing).

Additionally, young ophthalmologists are more likely to commit medication errors than the senior physicians, as suggested by the results of the prospective study conducted by Utman et al. [129]. This finding emphasizes the importance of training and prevention among residents in this topic.

The causes of medication errors could be divided into two categories, prescription errors and drug-related errors [127, 129]:

\section{Prescription errors}

(a) Erroneous patient information

(b) Erroneous format

(c) Unreadable prescription

(d) Unclear instructions

(e) Failure to note allergy status

2. Drug-related errors.

(a) Erroneous dosage

(b) Erroneous frequency

(c) Erroneous route of administration

\section{Preventive Strategies}

In the following are some strategies regarding writing of prescription to improve patient safety [128]:

- Include: date, patient name, drug name, dosage, route of administration, frequency, prescriber name and signature.

- Use capital letters.

- Avoid abbreviations (e.g., q.h.s., t.i.d., ...): instead transcribe in full (every night at bedtime, three times a day).

- Use the metric system.

- Use leading zero (0.1 instead of .1) and avoid trailing zero (2 instead of 2.0).

- If available, prefer computer-based prescribing systems (participates in decreasing the incidence of prescription errors [129-132]).

Finally, other types of error and their corresponding strategy are proposed by the AAO Quality of Care Secretariat. For example, regarding drugs with similar names, they propose to communicate the generic and brand name to minimize confusions. Other suggestions include limiting verbal orders to urgent situations when other ways of prescription orders are not available [128].

\subsection{Clinical Case}

We report the clinical case of a 45-year-old man who attended left eye (LE) cataract surgery in September 2019. The patient was allergic to Novocaine. The patient worked for a sewer and drain cleaning service. He was known for cardiovascular risk factors under treatment, with history of myocardial infarction and transitory ischemic attack a year prior to the event. He was pseudophakic in his right eye (RE).

The surgeon prescribed a preoperative therapy with eyelid cleansing pads and Bromfenac eye drops $0.9 \mathrm{mg} / \mathrm{ml}$, twice per day, 2 days before surgery. The day of the surgery, topical anesthesia without sedation and preoperative antisepsis were administered in the left eye. The surgeon performed small incisions, capsulorhexis, hydrodissection, and hydrodelineation. During phacoemulsification, 
wound burn of the tunnel occurred. During the whole procedure the patient was irritated and complained intraoperative pain. The tunnel where the wound burn occurred was sutured and the IOL was implanted. Due to the constant eye squeezing and scarce patient compliance, the surgeon decided not to inject intracameral cefuroxime, which was however used to irrigate the cornea. A contact lens was applied on the left eye.

Postoperative therapy included antibiotic and corticosteroid drops, four times per day each, and topical NSAIDs twice per day. The day after the operation corneal edema was present, and corticosteroids were increased to six times per day. No signs of anterior chamber inflammation were detected. A new visit was programmed in 7 days.

Three days after surgery, the patient came to the emergency room with left eye pain. The patient reported that he went back to work the day before. Visual acuity was light perception and the ocular examination detected a $4 \mathrm{~mm}$ hypopyon. The IOP was within normal limits. The eye fundus was not explorable. Endophthalmitis was diagnosed and the patient underwent a pars plana vitrectomy. During the surgery, corneal melting with perforation on the sutured wound burn was detected. The corneal suture was removed; vitreous and aqueous humor taps were collected and sent to the microbiology. The surgeon performed then a complete vitrectomy and Oxane was left as tamponade. Intravitreal injections of vancomycin and ceftazidime were performed. An amniotic membrane was sutured on the cornea. Postoperative therapy consisted in ciprofloxacin $500 \mathrm{mg}$ twice a day for 6 days, luxazone eye drops one drop four times a day for 15 days, fortified vancomycin $25 \mathrm{mg} / \mathrm{ml}$ eye drop one drop every $2 \mathrm{~h}$ and fortified tobramycin $14 \mathrm{mg} / \mathrm{ml}$ one drop every $2 \mathrm{~h}$.

At the 15-day visit visual acuity was still light perception, the amniotic membrane was correctly positioned and did not allow vision of the underlying structures. The therapy was changed based on the antibiogram sent by the microbiology that detected a Staphylococcus aureus infection. The surgeon prescribed tobramycin $0.3 \%$ /dexamethasone $0.1 \%$ one drop four times a day and ciprofloxacin drops $0.3 \%$ one drop four times a day.

An audit on the clinical case was successively discussed.

\subsubsection{Clinical Case Recommendations}

1. A good pre-anesthesia assessment of the patient is important. In fact, topical anesthesia without sedation is not always the appropriate technique for cataract surgery. A good anamnesis and examination are necessary to rule out the type of anesthesia that better suits the patient and ophthalmologist needs.

2. Whenever there are no contraindications, always inject $1 \mathrm{mg}$ cefuroxime in the anterior chamber since it contributes to prevent ocular infections.

3. Avoid premature return to the patient's work, especially if this condition exposes the operated eye to a high bacterial load.

4. Close follow-up is necessary for a high-risk patient.

5. Wound burns might complicate cataract surgery. They are a risk factor for endophthalmitis because of the continuing leakage, anterior chamber shallowing, corneo-scleral melting, and the possible presence of a corneal fistula. Performance of larger corneal incisions and adjustment of phacoemulsification settings can prevent this complication.

\subsection{Recommendations}

High-quality care and safety are important issues in ophthalmology. Prevention is crucial.

Knowledge of ophthalmic surgical complications and their management is fundamental, especially whenever a non-expert surgeon is operating.

Young ophthalmologists should consider the possibility of making medical errors in order to be cautious during daily practice.

Attention to guidelines and the use of a surgical checklist can help in reducing both adverse events and medical errors. Periodical check of the Ophthalmic Safety Alert website page from the Quality and Safe group is recommended to keep updated.

The educational process should involve different figures: the resident, who actively take part in the patient care; the trainers, who dedicate their 
time and knowledge to young doctors; and the hospital administration. In particular, wet labs and surgical simulators should be introduced in resident training. A proactive behavior is important to be adopted while on training.

Each program should have a structure that promotes safe, interprofessional, and team-based care [133]. Therefore, this is the duty of each resident and young trainee to know the different rules that apply for each individual program.

It is expected from residents to pay particular attention to patient safety. In facts, residents' perceptions of perioperative safety were defined as suboptimal in different scientific papers [120, $134,135]$. Establishing a culture of safety in ophthalmology and training young doctors in this field is important in order to improve patient care standards.

\subsection{Conclusion}

The purpose of this chapter was to sensitize young trainees to some of the most common adverse events and medical errors in ophthalmology with a special focus on surgery, and the tools to overcome such burden by presenting existing safety practices and strategies. We did not intend to be exhaustive, but we aimed to raise curiosity and self-awareness about this topic. Indeed, the occurrence of such events could have unacceptable consequences for the patient and severely impact young ophthalmologists that are building their career. We thus believe that the sooner we modify our behavior, the higher the impact on patient safety and on each individual future profession.

\section{References}

1. Kelly SP. Guidance on patient safety in ophthalmology from the Royal College of Ophthalmologists. Eye. 2009;23:2143.

2. Custer PL, Fitzgerald ME, Herman DC, Lee PP, Cowan CL, Cantor LB, et al. Building a culture of safety in ophthalmology. Ophthalmology. 2016;123:S40.

3. Foster A. Vision 2020: the cataract challenge. J Commun Eye Health. 2000;13(34):17-9.
4. Gollogly HE, Hodge DO, St. Sauver JL, Erie JC. Increasing incidence of cataract surgery: population-based study. J Cataract Refract Surg. 2013;39:1383.

5. Grzybowski A, Told R, Sacu S, Bandello F, Moisseiev E, Loewenstein A, et al. Update on intravitreal injections: Euretina Expert Consensus Recommendations. Ophthalmologica. 2018;239(4):181-93.

6. Hollingworth W, Jones T, Reeves BC, Peto T. A longitudinal study to assess the frequency and cost of antivascular endothelial therapy, and inequalities in access, in England between 2005 and 2015. BMJ Open. 2017;7(10):e018289.

7. Greenberg PB, Tseng VL, Wu WC, Liu J, Jiang $\mathrm{L}$, Chen $\mathrm{CK}$, et al. Prevalence and predictors of ocular complications associated with cataract surgery in United States veterans. Ophthalmology. 2011;118(3):507-14.

8. Pingree MF, Crandall AS, Olson RJ. Cataract surgery complications in 1 year at an academic institution. J Cataract Refract Surg. 1999;25(5):705-8.

9. Muhtaseb M, Kalhoro A, Ionides A. A system for preoperative stratification of cataract patients according to risk of intraoperative complications: a prospective analysis of 1441 cases. Br J Ophthalmol. 2004;88(10):1242-6.

10. Rutar T, Travis C, Porco AN. Risk factors for vitreous complications in resident-performed phacoemulsification surgery. Ophthalmology. 2009;116(3):431-6.

11. ACGME. Required minimum number of procedures for graduating residents in ophthalmology [Internet]. Accreditation Council for Graduate Medical Education (ACGME). 2013. Available from: https:// www.acgme.org/acgmeweb/Portals/0/PFAssets/ ProgramResources/240_Oph_Minimum_Numbers. pdf.

12. Fong CSU, Mitchell P, de Loryn T, Rochtchina E, Hong $\mathrm{T}$, Cugati $\mathrm{S}$, et al. Long-term outcomes of phacoemulsification cataract surgery performed by trainees and consultants in an Australian cohort. Clin Exp Ophthalmol. 2012;40(6):597-603.

13. Low SAW, Braga-Mele R, Yan DB, El-Defrawy $\mathrm{S}$. Intraoperative complication rates in cataract surgery performed by ophthalmology resident trainees compared to staff surgeons in a Canadian academic center. J Cataract Refract Surg. 2018;44(11):1344-9.

14. Oetting TA. Managing risk in cataract surgeries performed by resident ophthalmologists. Am Med Assoc J Ethics. 2010;12(12):913-6.

15. Thevi T, Godinho MA. Trends and complications of local anaesthesia in cataract surgery: an 8-year analysis of 12992 patients. Br J Ophthalmol. 2016;100:1708.

16. Guay J, Sales K. Sub-Tenon's anaesthesia versus topical anaesthesia for cataract surgery. Cochrane Database Syst Rev. 2015;(3):CD006291.

17. El-Hindy N, Johnston RL, Jaycock P, Eke T, Braga AJ, Tole DM, et al. The Cataract National Dataset 
electronic multi-centre audit of 55567 operations: anaesthetic techniques and complications. Eye. 2009;23(1):50-5.

18. Jaycock P, Johnston RL, Taylor H, Adams M, Tole DM, Galloway P, et al. The Cataract National Dataset electronic multi-centre audit of 55567 operations: updating benchmark standards of care in the United Kingdom and internationally. Eye. 2009;23:38.

19. Stein JD. Serious adverse events after cataract surgery. Curr Opin Ophthalmol. 2012;23(3):219-25.

20. Chakrabarti A, Nazm N. Posterior capsular rent: prevention and management. Indian J Ophthalmol. 2017;65:1359.

21. NICE. Cataracts in adults: management [Internet]. Cataracts in adults: management. 2017. Available from: https://www.nice.org.uk/guidance/ng77.

22. Schmidbauer JM, Vargas LG, Apple DJ, EscobarGomez M, Izak A, Arthur SN, et al. Evaluation of neodymium:yttrium-aluminum-garnet capsulotomies in eyes implanted with AcrySof intraocular lenses. Ophthalmology. 2002;109:1421.

23. Thompson AM, Sachdev N, Wong T, Riley AF, Grupcheva CN, McGhee CN. The Auckland Cataract Study: 2 year postoperative assessment of aspects of clinical, visual, corneal topographic and satisfaction outcomes. Br J Ophthalmol. 2004;88:1042.

24. Raj SM, Vasavada AR, Johar SRK, Vasavada VA, Vasavada VA. Post-operative capsular opacification: a review. Int J Biomed Sci. 2007;3(4):237-50.

25. Wormstone IM. Posterior capsule opacification: a cell biological perspective. Exp Eye Res. 2002;74(3):337-47.

26. Pandey SK, Apple DJ, Werner L, Maloof AJ, Milverton EJ. Posterior capsule opacification: a review of the aetiopathogenesis, experimental and clinical studies and factors for prevention. Indian $\mathrm{J}$ Ophthalmol. 2004;52:99-112.

27. Awasthi N, Guo S, Wagner BJ. Posterior capsular opacification: a problem reduced but not yet eradicated. Arch Ophthalmol. 2009;127:555.

28. Stein JD, Grossman DS, Mundy KM, Sugar A, Sloan FA. Severe adverse events after cataract surgery among medicare beneficiaries. Ophthalmology. 2011;118(9):1716-23.

29. Erie JC, Raecker ME, Baratz KH, Schleck CD, Robertson DM. Risk of retinal detachment after cataract extraction, 1980-2004: a population-based study. Trans Am Ophthalmol Soc. 2006;113(11):2026-32.

30. Kassem R, Greenwald Y, Achiron A, Hecht I, Man $\mathrm{V}$, Ben Haim L, et al. Peak occurrence of retinal detachment following cataract surgery: a systematic review and pooled analysis with internal validation. J Ophthalmol. 2018;2018:1.

31. Hermann MM, Kirchhof B, Fauser S. Temporal occurrence of retinal detachments after cataract surgery. Acta Ophthalmol. 2012;90(8):e594-6.

32. Neal RE, Bettelheim FA, Lin C, Winn KC, Garland DL, Zigler JS. Alterations in human vitreous humour following cataract extraction. Exp Eye Res. 2005;80(3):337-47.

33. Olsen T. The incidence of retinal detachment after cataract surgery. Open Ophthalmol J. 2012;6:79.
34. Haddad WM, Monin C, Morel C, Larricart P, Quesnot S, Ameline B, et al. Retinal detachment after phacoemulsification: a study of 114 cases. Am J Ophthalmol. 2002;133(5):630-8.

35. Bellan L, Ahmed IIK, MacInnis B, Mann C, Noël F, Sanmugasunderam S. Canadian Ophthalmological Society evidence-based clinical practice guidelines for cataract surgery in the adult eye. Can J Ophthalmol. 2008;43(Suppl. 1):S7-33.

36. Ray S, D'Amico DJ. Pseudophakic cystoid macular edema. Semin Ophthalmol. 2002;17:167.

37. Grzybowski A, Sikorski BL, Ascaso FJ, Huerva V. Pseudophakic cystoid macular edema: update 2016. Clin Interv Aging. 2016;11:1221-9.

38. Kim SJ, Schoenberger SD, Thorne JE, Ehlers JP, Yeh S, Bakri SJ, et al. Topical nonsteroidal antiinflammatory drugs and cataract surgery: a report by the American Academy of Ophthalmology. Ophthalmology. 2015;122:2159.

39. Lim BX, Lim CHL, Lim DK, Evans JR, Bunce C, Wormald R. Prophylactic non-steroidal antiinflammatory drugs for the prevention of macular oedema after cataract surgery. Cochrane Database of Systematic Reviews. 2016;11(11):CD006683.

40. Wielders LHP, Lambermont VA, Schouten JSAG, Van Den Biggelaar FJHM, Worthy G, Simons RWP, et al. Prevention of cystoid macular edema after cataract surgery in nondiabetic and diabetic patients: a systematic review and meta-analysis. Am J Ophthalmol. 2015;160:968.

41. Wielders LHP, Schouten JSAG, Winkens B, van den Biggelaar FJHM, Veldhuizen CA, Murta JCN, et al. European multicenter trial of the prevention of cystoid macular edema after cataract surgery in nondiabetics: ESCRS PREMED study report 1. J Cataract Refract Surg. 2018;44(4):429-39.

42. Obuchowska I, Mariak Z. Risk factors of massive suprachoroidal hemorrhage during extracapsular cataract extraction surgery. Eur J Ophthalmol. 2005; 15:712.

43. Eriksson A, Koranyi G, Seregard S, Philipson B. Risk of acute suprachoroidal hemorrhage with phacoemulsification. J Cataract Refract Surg. 1998;24:793.

44. Ling R, Cole M, James C, Kamalarajah S, Foot B, Shaw S. Suprachoroidal haemorrhage complicating cataract surgery in the UK: epidemiology, clinical features, management, and outcomes. Br J Ophthalmol. 2004;88(4):478-80.

45. Laube T, Brockmann C, Bornfeld N. Massive suprachoroidal hemorrhage: surgical management and outcome. GMS Ophthalmol Cases. 2015;5:Doc10.

46. Gower EW, Lindsley K, Tulenko SE, Nanji AA, Leyngold I, McDonnell PJ. Perioperative antibiotics for prevention of acute endophthalmitis after cataract surgery (Review). Cochrane Database Syst Rev. 2017;(2):CD006364.

47. Taban M, Behrens A, Newcomb RL, Nobe MY, Saedi G, Sweet PM, et al. Acute endophthalmitis following cataract surgery: a systematic review of the literature. Arch Ophthalmol. 2005;123(5):613-20. 
48. Barry P, Gettinby G, Lees F, Peterson M, Revie C, Seal D, et al. Prophylaxis of postoperative endophthalmitis following cataract surgery: results of the ESCRS multicenter study and identification of risk factors. J Cataract Refract Surg. 2007;33(6):978-88.

49. Group EVS. Results of the Endophthalmitis Vitrectomy study: a randomized trial of immediate vitrectomy and of intravenous antibiotics for the treatment of postoperative bacterial endophthalmitis. Arch Ophthalmol. 1995;113(12):1479-96.

50. Barry P, Cordovés L, Gardner S. ESCRS guidelines for prevention and treatment of endophthalmitis following cataract surgery. 2013. https://www.escrs. org/downloads/Endophthalmitis-Guidelines.pdf.

51. Kuhn F, Gini G. Complete and early vitrectomy for endophthalmitis (CEVE) as today's alternative to the endophthalmitis vitrectomy study. Vitr Surg. 2007:53-68.

52. Kuhn F, Gini G. Vitrectomy for endophthalmitis. Ophthalmology. 2006;113:714.

53. Olson RJ, Braga-Mele R, Chen SH, Miller KM, Pineda R, Tweeten JP, et al. Cataract in the adult eye preferred practice pattern. Am Acad Ophthalmol. 2017;124(2):P1-119.

54. Vogel A, Dick B, Krummenauer F. Reproducibility of optical biometry using partial coherence interferometry: intraobserver and interobserver reliability. J Cataract Refract Surg. 2001;27:1961.

55. Cavallini GM, Saccarola P, D'Amico R, Gasparin A, Campi L. Impact of preoperative testing on ophthalmologic and systemic outcomes in cataract surgery. Eur J Ophthalmol. 2004;14:369.

56. Keay L, Lindsley K, Tielsch J, Katz J, Schein O. Routine preoperative medical testing for cataract surgery (review). Cochrane Syst Rev. 2019;(1):CD007293.

57. The Royal College of Ophthalmologists. Cataract Surgery Guidelines 2010. The Royal College of Ophthalmologists: London, 2010. Available at: https:// www.rcophth.ac.uk/wp-content/uploads/2014/12/2010SCI-069-Cataract-Surgery-Guidelines-2010-SEPTEMBER-2010-1.pdf.

58. Butler TKH. Risk stratification and assessment in cataract surgery. J Cataract Refract Surg. 2012;38:184

59. Narendran N, Jaycock P, Johnston RL, Taylor H, Adams M, Tole DM, et al. The Cataract National Dataset electronic multicentre audit of 55567 operations: risk stratification for posterior capsule rupture and vitreous loss. Eye. 2009;23(1):31-7.

60. Kim BZ, Patel DV, Sherwin T, McGhee CNJ. The Auckland Cataract Study: assessing preoperative risk stratification systems for phacoemulsification surgery in a teaching hospital. Am J Ophthalmol. 2016;171:145-50.

61. Han JV, Patel DV, Wallace HB, Kim BZ, Sherwin T, McGhee CNJ. Auckland Cataract Study III: refining preoperative assessment with cataract risk stratification to reduce intraoperative complications. Am J Ophthalmol. 2019; https://doi.org/10.1016/j. ajo.2018.09.026.
62. Blomquist PH, Sargent JW, Winslow HH. Validation of Najjar-Awwad cataract surgery risk score for resident phacoemulsification surgery. J Cataract Refract Surg. 2010;36:1753.

63. Royal College. Local anaesthesia for ophthalmic surgery. Joint guidelines from the Royal College of Anaesthetists and the Royal College of Ophthalmologists. Curr Anaesth Crit Care. 2012.

64. Grzybowski A, Ascaso FJ, Kupidura-Majewski K, Packer M. Continuation of anticoagulant and antiplatelet therapy during phacoemulsification cataract surgery. Curr Opin Ophthalmol. 2015;26:28.

65. Benzimra JD, Johnston RL, Jaycock P, Galloway PH, Lambert G, Chung AKK, et al. The Cataract National Dataset electronic multicentre audit of 55 567 operations: antiplatelet and anticoagulant medications. Eye. 2009;23:10.

66. Barry P, Seal DV, Gettinby G, Lees F, Peterson M, Revie CW. ESCRS study of prophylaxis of postoperative endophthalmitis after cataract surgery. Preliminary report of principal results from a European multicenter study. J Cataract Refract Surg. 2006;32(3):407-10.

67. Speaker MG, Milch FA, Shah MK, Eisner W, Kreiswirth BN. Role of external bacterial flora in the pathogenesis of acute postoperative endophthalmitis. Ophthalmology. 1991;98(5):639-49.

68. Wood A, Conner R. Guideline for preoperative patient skin antisepsis. In: Guidelines for perioperative practice. Denver, CO: Association of Perioperative Registered Nurses; 2015.

69. Pathengay A, Flynn HW, Isom RF, Miller D. Endophthalmitis outbreaks following cataract surgery: causative organisms, etiologies, and visual acuity outcomes. J Cataract Refract Surg. 2012;38:1278.

70. Hellinger WC, Bacalis LP, Edelhauser HF, Mamalis $\mathrm{N}$, Milstein B, Masket S, et al. Recommended practices for cleaning and sterilizing intraocular surgical instruments. J Cataract Refract Surg. 2007;33(6):1095-100.

71. Tinley CG, Frost A, Hakin KN, McDermott W, Ewings P. Is visual outcome compromised when next day review is omitted after phacoemulsification surgery? A randomised control trial. $\mathrm{Br} \mathrm{J}$ Ophthalmol. 2003;87:1350.

72. Tan JHY, Newman DK, Klunker C, Watts SE, Burton RL. Phacoemulsification cataract surgery: is routine review necessary on the first post-operative day? Eye. 2000;14(Pt 1):53-5.

73. Borkar DS, Moustafa GA, Eton EA, Koulisis $\mathrm{N}$, Kloek CE, Borboli-Gerogiannis $\mathrm{S}$, et al. Incidence of unexpected peripheral retinal findings on dilated examination 1 month after cataract surgery: results in the Perioperative Care for Intraocular Lens Study. J Cataract Refract Surg. 2018;44:780.

74. Tan CS, Lim LW, Ting DS. The role of dilated fundus examination following cataract surgery. J Cataract Refract Surg. 2019;45(1):113. 
75. AAO. Ophthalmologist's duties concerning postoperative care policy statement. Am Acad Ophthalmol Policy statement. 2012.

76. Accreditation Council for Graduate Medical Education. ACGME program requirements for graduate medical education in ophthalmology [Internet]. 2020. Available from: https://www.acgme.org/Portals/0/PFAssets/ ProgramRequirements/240_Ophthalmology_2020. pdf?ver=2019-02-19-121341-650.

77. Spencer F. The Royal College of Ophthalmologists. Guide for delivery of Ophthalmic Specialist Training (OST). R Coll Ophthalmol. 2018.

78. International Council of Ophthalmologists. International Council of Ophthalmology residency curriculum. 2016. icoph.org/curricula.html.

79. Alfawaz AM. Ophthalmology resident surgical training: can we do better? Saudi J Ophthalmol. 2019;33(2):159-62.

80. Le K, Bursztyn L, Rootman D, Harissi-Dagher M. National survey of Canadian ophthalmology residency education. Can J Ophthalmol. 2016;51(3):219-25.

81. The Royal College of Ophthalmologists. Practice guidance: cataract surgery guidelines. 2010. www. rcophth.ac.uk.

82. Belyea DA, Brown SE, Rajjoub LZ. Influence of surgery simulator training on ophthalmology resident phacoemulsification performance. J Cataract Refract Surg. 2011;37:1756.

83. Staropoli PC, Gregori NZ, Junk AK, Galor A, Goldhardt R, Goldhagen BE, et al. Surgical simulation training reduces intraoperative cataract surgery complications among residents. Simul Healthc. 2018;13(1):11-5.

84. Nauck M, Roth M, Tamm M, Eickelberg O, Wieland $\mathrm{H}$, Stulz $\mathrm{P}$, et al. Induction of vascular endothelial growth factor by platelet-activating factor and platelet-derived growth factor is downregulated by corticosteroids. Am J Respir Cell Mol Biol. 1997; 16:398.

85. Ladas ID, Karagiannis DA, Rouvas AA, Kotsolis AI, Liotsou A, Vergados I. Safety of repeat intravitreal injections of bevacizumab versus ranibizumab: our experience after 2,000 injections. Retina. 2009;29:313.

86. Brouzas D, Koutsandrea C, Moschos M, Papadimitriou S, Ladas I, Apostolopoulos M. Massive choroidal hemorrhage after intravitreal administration of bevacizumab for AMD followed by controlateral sympathetic ophthalmia. Clin Ophthalmol. 2009;3:457-9.

87. Karagiannis DA, Mitropoulos P, Ladas ID. Large subretinal haemorrhage following change from intravitreal bevacizumab to ranibizumab. Ophthalmologica. 2009;223(4):279-82.

88. Mason JO, Frederick PA, Neimkin MG, White MF, Feist RM, Thomley ML, et al. Incidence of hemorrhagic complications after intravitreal bevacizumab (Avastin) or ranibizumab (Lucentis) injections on systemically anticoagulated patients. Retina. 2010;30:1386.
89. McCannel CA. Meta-analysis of endophthalmitis after intravitreal injection of anti-vascular endothelial growth factor agents: causative organisms and possible prevention strategies. Retina. 2011;31:654

90. Scott IU, Flynn HW. Reducing the risk of endophthalmitis following intravitreal injections. Retina. 2007;27(1):10-2.

91. Ferraz D, Bressanim G, Takahashi B, Pelayes D, Takahashi W. Three-monthly intravitreal bevacizumab injections for neovascular age-related macular degeneration: short-term visual acuity results. Eur J Ophthalmol. 2010;20:740.

92. Sodré SL, Barbosa IAF, Pacheco IE, Ferreira F d QT, David MA, Nascimento MA, et al. Costs and benefits of bevacizumab vial sharing for the treatment of retinal diseases. BMC Public Health. 2019; https:// doi.org/10.1186/s12889-019-7562-y.

93. Falavarjani KG, Nguyen QD. Adverse events and complications associated with intravitreal injection of anti-VEGF agents: a review of literature. Eye (Basingstoke). 2013;27(7):787-94.

94. Menchini F, Toneatto G, Miele A, Donati S, Lanzetta P, Virgili G. Antibiotic prophylaxis for preventing endophthalmitis after intravitreal injection: a systematic review. Eye (Basingstoke). 2018;32(9):1423-31.

95. Tolentino M. Systemic and ocular safety of intravitreal anti-VEGF therapies for ocular neovascular disease. Surv Ophthalmol. 2011;56:95.

96. Hahn P, Kim JE, Stinnett S, Chung MM, Dugel PU, Flynn HW, et al. Aflibercept-related sterile inflammation. Ophthalmology. 2013;3(9):753-9.

97. Mezad-Koursh D, Goldstein M, Heilwail G, ZayitSoudry S, Loewenstein A, Barak A. Clinical characteristics of endophthalmitis after an injection of intravitreal antivascular endothelial growth factor. Retina. 2010;30(7):1051-7.

98. Meyer CH, Michels S, Rodrigues EB, Hager A, Mennel S, Schmidt JC, et al. Incidence of rhegmatogenous retinal detachments after intravitreal antivascular endothelial factor injections. Acta Ophthalmol. 2011;89(1):70-5.

99. Bakri SJ, Pulido JS, McCannel CA, Hodge DO, Diehl N, Hillemeier J. Immediate intraocular pressure changes following intravitreal injections of triamcinolone, pegaptanib, and bevacizumab. Eye. 2009;23(1):181-5.

100. Demirel S, Yanik O, Batioglu F, Ozmert E. Intraocular pressure changes related to intravitreal injections of ranibizumab: analysis of pseudophakia and glaucoma subgroup. Int Ophthalmol. 2014;35(4):541-7.

101. Mazzarella S, Mateo C, Freixes S, Burés-Jelstrup A, Rios J, Navarro R, et al. Effect of intravitreal injection of dexamethasone $0.7 \mathrm{mg}$ (Ozurdex $®)$ on intraocular pressure in patients with macular edema. Ophthalmic Res. 2015;54(3):143-9.

102. Urban RC, Cotlier E. Corticosteroid-induced cataracts. Surv Ophthalmol. 1986;1(2):102-10.

103. He Y, Ren XJ, Hu BJ, Lam WC, Li XR. A metaanalysis of the effect of a dexamethasone intravitreal 
implant versus intravitreal anti-vascular endothelial growth factor treatment for diabetic macular edema. BMC Ophthalmol. 2018;18(1):121.

104. RCO. Ophthalmic Service Guidance. Intravitreal injection therapy. R Coll Ophthalmol. 2018;1-16.

105. NHS Improvement. Never events list 2018. 2018;22. Available from: https:// improvement.nhs.uk/documents/2266/ Never_Events_list_2018_FINAL_v5.pdf.

106. Simon JW, Ngo Y, Khan S, Strogatz D. Surgical confusions in ophthalmology. Arch Ophthalmol. 2007; 125(11):1515-22.

107. Schein OD, Cassard SD, Tielsch JM, Gower EW. Cataract surgery among medicare beneficiaries. Ophthal Epidemiol. 2012;19(5):257-64.

108. Bhan A, Dave D, Vernon SA, Bhan K, Bhargava J, Goodwin H. Risk management strategies following analysis of cataract negligence claims. Eye. 2005;19(3):264-8.

109. Neily J, Mills PD, Eldridge N, Dunn EJ, Samples $\mathrm{C}$, Turner JR, et al. Incorrect surgical procedures within and outside of the operating room. Arch Surg. 2009;144(11):1028-34.

110. Thompson AC, Parikh PD, Lad EM. Review of ophthalmology medical professional liability claims in the United States from 2006 through 2015. Ophthalmology. 2018;125(5):631-41.

111. Ali N, Little BC. Causes of cataract surgery malpractice claims in England 1995-2008. Br J Ophthalmol. 2011;95(4):490.

112. International Council of Ophthalmology. ICO's global call for action to eliminate eye surgical errors [Internet]. International Council of Ophthalmology. 2016. Available from: http://www.icoph.org/downloads/ICO_Global_Call_for_Action_to_Eliminate_ Eye_Surgical_Errors.pdf.

113. Ali N. A decade of clinical negligence in ophthalmology. BMC Ophthalmol. 2007;7:20.

114. Reason J. Human error: models and management. Br Med J. 2000;320:768.

115. Perneger TV. The Swiss cheese model of safety incidents: are there holes in the metaphor? BMC Health Serv Res. 2005;5:1-7.

116. Hempel S, Maggard-Gibbons M, Nguyen DK, Dawes AJ, Miake-Lye I, Beroes JM, et al. Wrongsite surgery, retained surgical items, and surgical fires a systematic review of surgical never events. JAMA Surg. 2015;50(8):796-805.

117. Parikh R, Palmer V, Kumar A, Simon JW. Surgical confusions in ophthalmology: description, analysis, and prevention of errors from 2006 through 2017. Ophthalmology. 2019;127(3):296-302.

118. World Health Organization. WHO guidelines for safe surgery. Geneva: WHO; 2009. p. 2009.

119. AAO Wrong-Site Task Force. Recommendations of American Academy of Ophthalmology Wrong-Site Task Force - 2014 [Internet]. American Academy of Ophthalmology. 2014. Available from: https://www. aao.org/patient-safety-statement/recommendationsof-american-academy-ophthalmology-

120. Kilduff CLS, Leith TO, Drake TM, Fitzgerald JEF. Surgical safety checklist training: a national study of undergraduate medical and nursing student teaching, understanding and influencing factors. Postgrad Med J. 2018;94:143.

121. Chen AJ, Havnaer AG, Greenberg PB. Training in the prevention of surgical errors in ophthalmology: the resident perspective. J Cataract Refract Surg. 2014;40:2157.

122. Mathew RG, Ferguson V, Hingorani M. Clinical negligence in ophthalmology: fifteen years of National Health service litigation authority data. Ophthalmology. 2013;120:859.

123. Beckman HB, Markakis KM, Suchman AL, Frankel RM. The doctor-patient relationship and malpractice. Lessons from plaintiff depositions. Arch Intern Med. 1994;154(12):1365-70.

124. Zamir E, Beresova-Creese K, Miln L. Intraocular lens confusions: a preventable "never event" - the Royal Victorian Eye and Ear Hospital Protocol. Surv Ophthalmol. 2012;57:430.

125. National Coordinating Council for Medication Error Reporting and Prevention. About medication errors. What is a medication error? NCCMERP. 2016.

126. Schappert SM, Nelson C. National ambulatory medical care survey: 1995-96 summary. Vital Heal Stat Ser 13 Data Heal Resour Util; 1999.

127. Mandal K, Fraser SG. The incidence of prescribing errors in an eye hospital. BMC Ophthalmol. 2005;5:4.

128. AAO Quality of Care Secretariat. Minimizing medication errors: communication about drug orders - 2015 [Internet]. American Academy of Ophthalmology. 2015. Available from: https://www. aao.org/patient-safety-statement/minimizing-medication-errors-communication-about-d.

129. Utman SAK, Atkinson PL, Baig HM. Methods to reduce prescription errors in ophthalmic medication. Saudi J Ophthalmol. 2013;27:267.

130. Papshev D, Peterson AM. Electronic prescribing in ambulatory practice: promises, pitfalls, and potential solutions. Am J Manag Care. 2001;7(7):725-36.

131. S.T C. Electronic prescribing: a review of costs and benefits. Top Health Inf Manage; 2003.

132. Nightingale PG, Adu D, Richards NT, Peters M. Implementation of rules based computerised bedside prescribing and administration: intervention study. BMJ. 2000;320(7237):750-3.

133. Accreditation Council for Graduate Medical Education. Program requirements for graduate medical education in ophthalmology [Internet]. 2019. Available from: https:// www.acg me.org/Portals / $/$ PFAs set s/ ProgramRequirements/240-Ophthalmology_2019. pdf?ver=2018-08-21-132333-400.

134. Putnam LR, Levy SM, Kellagher CM, Etchegaray JM, Thomas EJ, Kao LS, et al. Surgical resident education in patient safety: where can we improve? J Surg Res. 2015;199(2):308-13.

135. Alper E, Rosenberg EI, O'Brien KE, Fischer M, Durning SJ. Patient safety education at U.S. and Canadian medical schools: results from the 2006 clerkship directors in internal medicine survey. Acad Med. 2009;84(12):1672-6. 
Open Access This chapter is licensed under the terms of the Creative Commons Attribution 4.0 International License (http://creativecommons.org/licenses/by/4.0/), which permits use, sharing, adaptation, distribution and reproduction in any medium or format, as long as you give appropriate credit to the original author(s) and the source, provide a link to the Creative Commons license and indicate if changes were made.

The images or other third party material in this chapter are included in the chapter's Creative Commons license, unless indicated otherwise in a credit line to the material. If material is not included in the chapter's Creative Commons license and your intended use is not permitted by statutory regulation or exceeds the permitted use, you will need to obtain permission directly from the copyright holder.

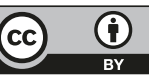

